\title{
Learning discloses abnormal structural and functional plasticity at hippocampal synapses in the APP23 mouse model of Alzheimer's disease
}

\author{
Silvia Middei, ${ }^{1,7}$ Anna Roberto, ${ }^{1}$ Nicola Berretta, ${ }^{2}$ Maria Beatrice Panico, ${ }^{3}$ Simone Lista, ${ }^{4}$ \\ Giorgio Bernardi, ${ }^{2,5}$ Nicola B. Mercuri, ${ }^{2,5}$ Martine Ammassari-Teule, ${ }^{1}$ and \\ Robert Nisticò ${ }^{2,6}$ \\ ${ }^{1}$ CNR Institute for Neuroscience, S. Lucia Foundation, Rome 00143, Italy; ${ }^{2}$ Laboratory of Experimental Neurology, S. Lucia Foundation, \\ Rome 00143, Italy; ${ }^{3}$ Pharmaceutical Biotechnology Center, University of Rome Tor Vergata, 00133 Rome, Italy; ${ }^{4}$ Laboratory of \\ Experimental Neurobiology, I.R.C.C.S. Casimiro Mondino Institute of Neurology Foundation, 27100 Pavia, Italy; ${ }^{5}$ Department of \\ Neuroscience, University of Rome Tor Vergata, 00133 Rome, Italy; ${ }^{6}$ Department of Pharmacobiology and University \\ Centre for Adaptive Disorders and Headache (UCHAD), University of Calabria, 87036 Rende, Italy
}

\begin{abstract}
B6-Tg/ThylAPP23Sdz (APP23) mutant mice exhibit neurohistological hallmarks of Alzheimer's disease but show intact basal hippocampal neurotransmission and synaptic plasticity. Here, we examine whether spatial learning differently modifies the structural and electrophysiological properties of hippocampal synapses in APP23 and wild-type mice. While no genotypic difference was found in the pseudotrained mice, training elicited a stronger increase in spine density and a more rapid decay of long-term potentiation (LTP) in APP23 mutants. Thus, learning discloses mutation-related abnormalities regarding dendritic spine formation and LTP persistence, thereby suggesting that although unaltered in naîve synapses, plasticity becomes defective at the time it comes into play.
\end{abstract}

Alzheimer's disease $(\mathrm{AD})$ is a progressive neurodegenerative disorder characterized by cognitive deficits and extensive neuronal loss (Selkoe and Schenk 2003). Neuropathological alterations identified postmortem in $\mathrm{AD}$ patients include beta-amyloid $(\mathrm{A} \beta)$ plaques, intracellular neurofibrillary tangles due to hyperphosphorylation of the tau protein, reduced synaptic density, inflammation, and extensive cell death in brain regions critically involved in learning and memory. Although these alterations can be separately or jointly triggered in transgenic mouse models of $\mathrm{AD}$, concomitant cognitive dysfunction and neural plasticity abnormalities are subtly present in the majority of these models. For example, heterozygous B6-Tg/Thy1APP23Sdz (APP23) mice overexpressing human amyloid precursor protein (APP) with AD-linked mutations (Sturchler-Pierrat et al. 1997) show substantial amyloid plaque deposits in the hippocampus at $\sim 12$ mo and the presence of distorted neurites containing hyperphosphorylated tau that strongly alter their brain vasculature (Meyer et al. 2008). At this time point, however, APP23 mice display normal hippocampal long-term potentiation (LTP) (Roder et al. 2003) and an intact number of neocortical synaptic boutons (Boncristiano et al. 2005). In addition, careful assessment of their learning abilities reveals that the impairments they show in a variety of hippocampal-dependent tasks reflect a delay in learning rather than an incapability to learn (Lalonde et al. 2002; Kelly et al. 2003; Syková et al. 2005; Vloeberghs et al. 2006).

Support for the view that the APP23 mutation might not induce massive cognitive deficits comes from recent data showing that APP23 and wild-type mice perform similarly in a simple

${ }^{7}$ Corresponding author.

Email s.middei@hsantalucia.it; fax 39-06501703320.

Article is online at http://www.learnmem.org/cgi/doi/10.1101//m.1748310. radial eight-arm maze. However, performance impairments emerge in the mutant mice when the task is turned into a more complex spatial problem, raising the possibility that the previous negative findings were due to insufficient challenge of their learning capabilities. Importantly, assessment of nerve growth factor (NGF), brain-derived neurotrophic factor (BDNF), and neurotrophin-3 (NT-3) levels after each learning experience reveals no variation between genotypes following simple radial maze training, but a decrease in BDNF content in APP23 mice following complex radial maze training (Hellweg et al. 2006). This finding points out that biological markers of $\mathrm{AD}$ can be altered upon challenge, although basal levels are unchanged, in turn suggesting that the absence of mutation effects on baseline plasticity does not necessarily mean that plasticity is intact at the time it comes into play.

Reorganization of neuronal networks in selective brain areas is thought to represent the physiological basis of learning and memory. Changes in strength and efficacy of existing synapses (i.e., LTP-like mechanisms) together with the formation of new synapses and elimination of old ones resulting from structural remodeling of dendritic material are widely accepted as putative mechanisms for these processes. There is evidence that hippocampal-dependent learning enhances spine density in the CA1 and dentate gyrus regions of the hippocampus (Knafo et al. 2001, 2004; Leuner et al. 2003; Restivo et al. 2006, 2009). Interestingly, hippocampal-dependent learning also modifies CA1 basal synaptic transmission (Sacchetti et al. 2001; Lange-Asschenfeldt et al. 2007; Makhracheva-Stepochkina et al. 2008) and LTP (Sacchetti et al. 2002; Lange-Asschenfeldt et al. 2007), although differences in the direction of the alterations (occlusion vs. potentiation), likely depending on the protocols used, have been reported. Based on the above findings, the present study investigates the possibility that hippocampal structural 
and synaptic plasticity alterations emerge in APP23 mice under learning challenge. We therefore trained or pseudotrained APP23 mutant mice and their wild-type controls in the spatial version of the water maze task and then examined the impact of training on spine density, synaptic transmission, and LTP in both genotypes.

The water maze was a white circular tank $(104 \mathrm{~cm}$ in diameter) filled with opaque water $\left(22^{\circ} \mathrm{C}-23^{\circ} \mathrm{C}\right)$. A platform made of gray plastic material $(12 \mathrm{~cm}$ in diameter) was submerged $0.5 \mathrm{~cm}$ below the water surface and $13 \mathrm{~cm}$ from the edge of the tank. The tank was surrounded by four curtains at a distance of $50 \mathrm{~cm}$, with each curtain bearing a distinct cue card $(20 \times$ $20 \mathrm{~cm}$ ). The protocol (Middei et al. 2007) consisted of two daily habituation sessions and three daily training sessions of four trials each. On each trial, mice were released from one of four fixed points according to a sequence varying randomly and left swimming until they reached the platform and rested on it for at least $1 \mathrm{~min}$. Intertrial intervals lasted $3 \mathrm{~min}$. The latency to reach the submerged platform, the distance traveled, and the swimming speed were recorded by means of a computer-based video tracking system (Ethovision, Noldus) and compared by means of one-way ANOVAs for repeated measures with "genotype" as the main factor and "sessions" as the repeated factor. For each trained mouse, one pseudotrained mouse was allowed to swim the same amount of time, but in a smaller tank $(60 \mathrm{~cm}$ in diameter) located in another room. This tank was also surrounded with curtains, but with no cue cards attached. Twenty-four hours following the last training sessions, the mice were deeply anaesthetized with halothane and then killed by cervical dislocation. Their brains were collected, split in two hemispheres, and randomly assigned to morphological and electrophysiological experiments.

We first observed that spatial learning was less proficient in APP23 mice. As shown in Figure 1A, although all the trained mice showed a reduction in the latency to find the submerged platform over the $3 \mathrm{~d}$ of training (sessions effect, $F_{(2,20)}=11.16$, $P<0.001$ ), latencies were globally higher in APP23 mice (genotype effect, $\left.F_{(1,10)}=9.02, P<0.05\right)$, especially on day $2(P<$ $0.05)$. The learning impairment of the mutant mice was confirmed by the analysis of the distance traveled to reach the platform (Fig. 1B). A genotype $\times$ session interaction $\left(F_{(2,20)}=3.76\right.$, $P<0.05)$ was found for this variable, indicating that APP23 mice traveled a longer distance than wild-type mice, mainly on day $2(P<0.05)$. These differences in performance cannot be ascribed to motor alterations since the swimming velocity (Fig. 1C) did not differ between groups (genotype effect, $F_{(1,10)}=$ $3.03, P=\mathrm{NS}$ ). All the mice, however, performed similarly on the last day of training, thus confirming that the APP23 mutation overall produces a delay in learning (Lalonde et al. 2002; Kelly et al. 2003; Syková et al. 2005; Vloeberghs et al. 2006).

Modifications of neuronal connections occur in several regions of the mammalian brain in response to learning (for review, see Kolb and Whishaw 1998). The mouse hippocampus is especially prone to showing learning-induced structural changes (Restivo et al. 2006, 2009) that tightly correlate with enhanced BDNF levels (Okuno et al. 1999). We therefore compared spine density on apical dendrites of pyramidal neurons lying in the CA1 region of the hippocampus in control cage, pseudotrained, and trained mice from both genotypes (Fig. 2A). Hippocampal tissue was processed for Golgi-Cox staining according to a previously described protocol (Restivo et al. 2006). Four to six neurons were selected from each brain under high magnification $(100 \times)$ using a Leica (DMLB) microscope. Neurolucida Software (MicroBrightField) connected to the Leica microscope was used to trace apical dendrites of CA1 pyramidal neurons. Spine density counting (number of spines per $1 \mu \mathrm{m}$ length) was performed on eight $20-\mu \mathrm{m}$ segments on secondary and tertiary branches of dendrites from each selected neuron. In the trained and pseudotrained groups, spine density was plotted as the increase relative to baseline (control cage mice), and values were compared among groups by means of a two-way ANOVA with "genotype" and "training condition" as main factors. We first observed that spine density in control cage mice did not vary between genotypes $\left(t_{(46)}=0.53, P=\mathrm{NS}\right.$, data not shown). Then, consistent with previous reports indicating that water maze training elicits hippocampal structural changes (O'Malley et al. 2000; Eyre et al. 2003; Middei et al. 2007), we found a post-training increase in spine density on CA1 hippocampal neurons in both genotypes (Fig. 2B,C). Specifically, analyses performed on trained and pseudotrained mice data expressed as the percentage increase relative to baseline revealed no effect of the genotype $\left(F_{(1,92)}=\right.$ $3.35, P=\mathrm{NS})$, but did show an effect of the training condition $\left(F_{(1,92)}=17.53, P<0.001\right)$, with more spines counted in the trained groups. Notably, spine density was also enhanced in the pseudotrained mice compared with control mice. This increase can be the result of some form of nonassociative contextual learning previously found to elicit mild but significant hippocampal structural remodeling (Restivo et al. 2009). Importantly, post hoc comparisons showed that the increase in spines generated by the learning experience was stronger in APP23 mice than in the wild-type mice $(P<0.05)$. We can speculate that this major increment might reflect some form of compensatory mechanism indicating, for instance, that learning was more effortful in the mutant mice and therefore to induce stronger reactive structural plasticity. Consistent with this view, APP23 mice reared
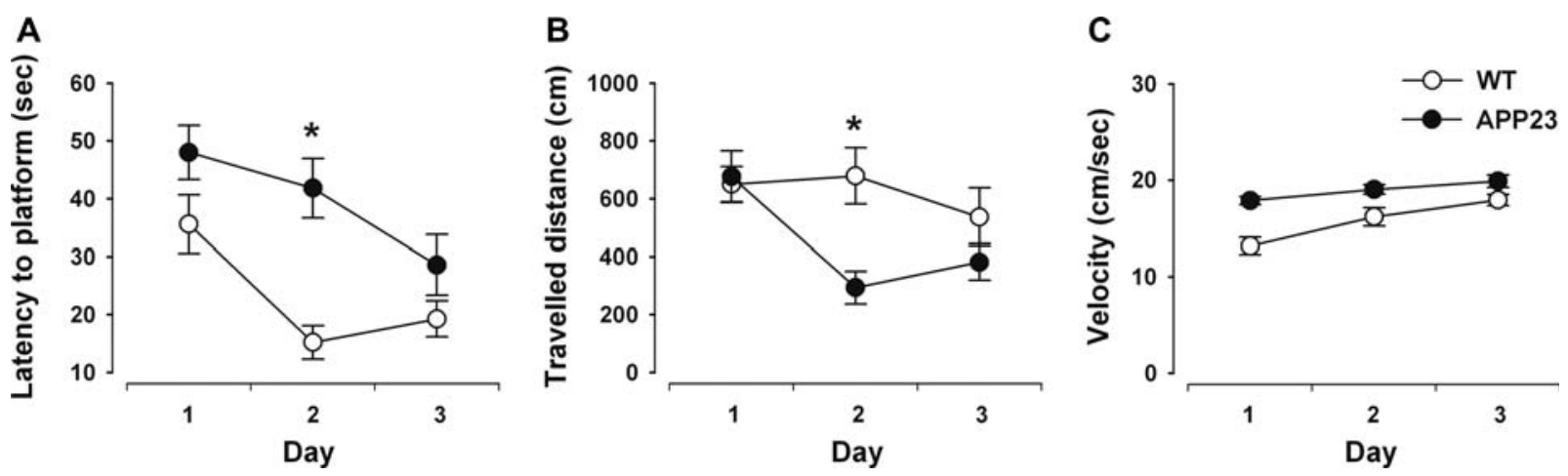

Figure 1. Water maze performance in APP23 heterozygous mutant $(n=6)$ and wild-type $($ WT) $(n=6)$ mice. $(A)$ The latency to reach the submerged platform decreased in each genotype as training proceeded but remained significantly higher in APP23 mice, especially on day 2 . ( $B$ ) APP23 mice traveled a longer distance compared with wild-type mice with the main difference emerging on day 2 . (C) Swimming velocity did not significantly vary between genotypes. $\left(^{*}\right) P<0.05$. 
in an enriched environment do not merely show intact activitydependent regulation of neurogenesis, but possess an overproportion of progenitor cells indicative of an increased propensity to form new neurons (Mirochnic et al. 2009).

To identify the functional state of these differently learningremodeled circuits, we compared synaptic transmission and CA1-LTP between mice undergoing training or pseudotraining. Hippocampal slices ( $400 \mu \mathrm{m}$ thick) were prepared using standard techniques and maintained in a submerged recording chamber (at $\left.30^{\circ} \mathrm{C}\right)$ perfused with oxygenated $\left(95 \% \mathrm{O}_{2}-5 \% \mathrm{CO}_{2}\right)$ artificial cerebrospinal fluid (ACSF) containing $124 \mathrm{mM} \mathrm{NaCl}, 3 \mathrm{mM} \mathrm{KCl}$, $26 \mathrm{mM} \mathrm{NaHCO}, 1.25 \mathrm{mM} \mathrm{NaH} \mathrm{PO}_{4}, 2.4 \mathrm{mM} \mathrm{CaCl}, 1.2 \mathrm{mM}$ $\mathrm{MgSO}_{4}$, and $10 \mathrm{mM}$ glucose. After allowing slices to recover for at least $1 \mathrm{~h}$, a bipolar, nichrome wire stimulating electrode was placed in the stratum radiatum of the hippocampal CA1 region to activate Schaffer collateral-commissural fiber synapses, and an extracellular glass microelectrode filled with ACSF (resistance 5-10 M $\Omega$ ) was used to record evoked field excitatory postsynaptic potentials (fEPSP).

We first assessed the effect of spatial training on basal synaptic transmission by comparing input/output (I/O) curves between APP23 mice and their wild-type littermates. Specifically, we plotted the size of presynaptic fiber volleys (input) against the slopes of fEPSPs (output) measured from responses generated by different intensities of presynaptic fiber stimulation and compared the angular coefficient of the I/O slopes by means of Student $t$-tests. We found that the slopes generated for both genotypes overlapped and were not significantly different either in the pseudotraining $\left(t_{(8)}=1.85, P=\mathrm{NS}\right)$ or the training $\left(t_{(12)}=0.18, P=\right.$ NS) condition (Fig. 3A). Interestingly, I/O curves were significantly lower in the training than in the pseudotraining condition in APP23 $\left(t_{(10)}=6.14, P<0.001\right)$ and wild-type mice $\left(t_{(10)}=8.75\right.$, $P<0.001)$, indicating that only associative spatial learning saturated hippocampal synapses and occluded basal synaptic responses. We then explored whether paired-pulse facilitation (PPF), known to reflect a presynaptic mechanism (Zucker and Regehr 2002), varied among the four groups under observation. PPF produced by the baseline stimulation intensity was tested at interpulse intervals of 20,50, 100, 200, and $500 \mathrm{msec}$ and compared by means of a two-way ANOVA with "genotype" and "training" condition as main factors. No difference in the paired-pulse ratio depending on the genotype $\left(F_{(1,20)}=0.09, P=\mathrm{NS}\right)$ or the training condition $\left(F_{(1,20}=2.31, P=\mathrm{NS}\right)$ was found (Fig. 3B). The finding that training reduced to the same extent the fEPSP slope in both genotypes confirms that learning restrains the susceptibility of synapses to be recruited by presynaptic fiber stimulation (Lange-Asschenfeldt et al. 2007; Makhracheva-Stepochkina et al. 2008). We exclude that this phenomenon is due to an alteration of presynaptic mechanisms since it was not associated with PPF modifications.

Next, we assessed CA1-LTP induced by a high-frequency stimulation (HFS) protocol (1 train, $100 \mathrm{~Hz}, 1 \mathrm{sec}$; baseline stimulation intensity corresponding to $50 \%$ of maximal EPSP amplitude) and observed that this protocol elicited the same amount of LTP in all experimental conditions. As shown in Figure $3 \mathrm{C}$, in the pseudotrained mice, synaptic potentiation measured 50-60 min after application of HFS was $44.9 \pm 6.3 \%$ above baseline in wild-type slices $(n=5)$ and $39.2 \pm 4.9 \%$ in mutant slices $(n=5)$. Statistical comparison of these values compared by means of a two-way ANOVA with "genotype" and "training" condition as main factors did not reveal any significant genotypic difference in LTP induction $\left(F_{(1,8)}=0.53, \quad P=\mathrm{NS}\right)$. Although we used a slightly different protocol for LTP induction compared with Roder et al. (2003), our data confirm that LTP develops normally in APP23 mutants. However, although LTP was similarly induced in both genotypes, APP23 mice showed a regularly decaying potentiation that recovered just above baseline $1 \mathrm{~h}$ after HFS was applied. In fact, the average LTP measured 50-60 min post-tetanus was $52.7 \pm 7.6 \%$ above baseline in wild-type slices $(n=6)$ 
A

pseudo-TR

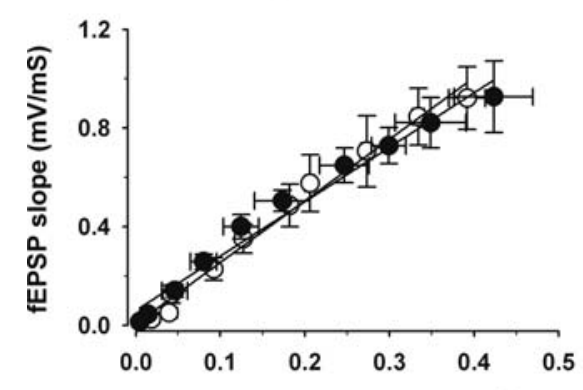

TR

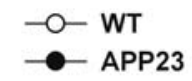

fiber volley amplitude $(\mathrm{mV})$

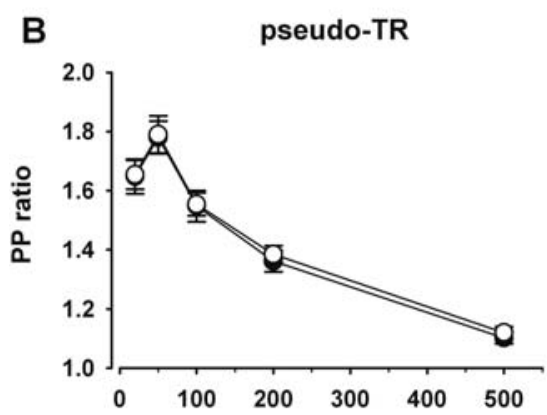

TR

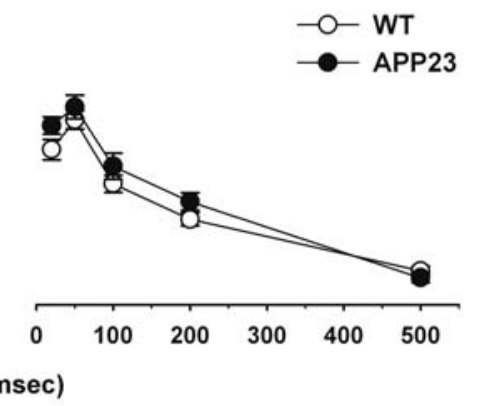

C
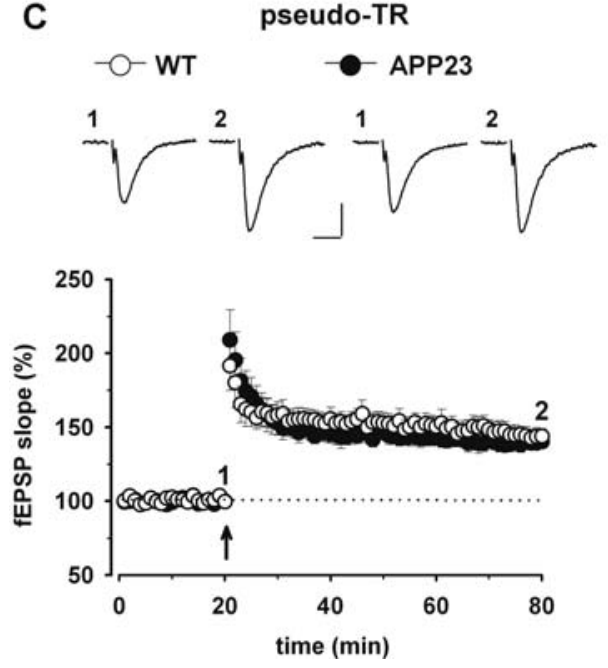

TR
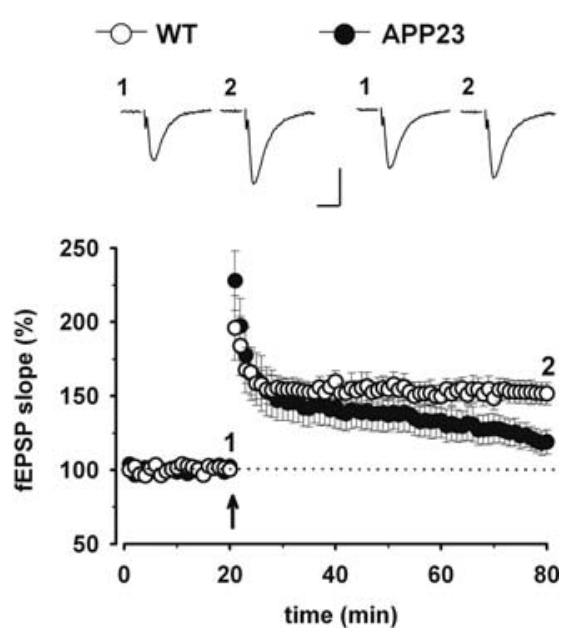

Figure 3. Synaptic transmission and plasticity in APP23 heterozygous mutant and wild-type (WT) mice undergoing pseudotraining (pseudo-TR) ( $n=5$ slices from five WT mice; $n=5$ slices from five APP23 mice) or training (TR) ( $n=6$ slices from six WT mice; $n=6$ slices from six APP23 mice). (A) Input/output $(\mathrm{I} / \mathrm{O})$ curves established by plotting the fEPSP values against presynaptic fiber volley amplitudes at increasing stimulus strengths in hippocampal slices of APP23 and WT mice undergoing pseudo-TR and TR. No genotypic difference was found, but I/O curves were occluded in the TR condition. $(B)$ Superimposed pooled data showing the paired-pulse ratio \pm SEM against the paired-pulse interval in hippocampal slices of WT and APP23 mice undergoing pseudo-TR and TR. Each pool of data represents at least seven recordings per mouse. The facilitation ratio (slope of second EPSP/ slope of first EPSP) was plotted as a function of interpulse interval (20,50, 100, 200, and $500 \mathrm{msec}$ ). At every interval, the curves obtained in each experimental condition overlapped. (C) Superimposed pooled data showing the normalized changes in field potential slope $( \pm$ SEM) induced by highfrequency stimulation (HFS) protocol $(100 \mathrm{~Hz}$ for $1 \mathrm{sec})$ in hippocampal slices of APP23 and WT mice undergoing pseudo-TR or TR. fEPSP slopes were expressed as the percentage of the pre-tetanus baseline. Representative fEPSPs traces before and $60 \mathrm{~min}$ after the induction of LTP are shown. Although LTP was normally induced in all experimental conditions, the degree of potentiation measured 50-60 min after HFS was significantly lower in trained APP23 compared with trained WT. fEPSPs calibration bars: $0.5 \mathrm{mV}, 10 \mathrm{msec}$.

compared with $22.8 \pm 8.6 \%$ in $\mathrm{APP} 23$ mice $(n=6)$ (genotype effect, $F_{(1,8)}=$ 6.85, $P<0.001 ;$ Fig. 3C). Since recordings took place at least $24 \mathrm{~h}$ after completion of training, we conclude that learning unmasks a LTP deficit at CA1 synapses that is specific to the mutant mice. Among the downstream signaling mechanisms regulating LTP maintenance, BDNF is known to be crucial (Abraham and Williams 2008), and, consistent with a role for diminished levels of this neurotrophin in the LTP decay of trained APP23 mutants, hippocampal BDNF content was found to be reduced after these mice were trained in a complex spatial task (Hellweg et al. 2006).

The absence of post-training LTP alterations in the wild-type mice seems to disagree with data showing that synaptic plasticity was either occluded (Sacchetti et al. 2002) or enhanced (LangeAsschenfeldt et al. 2007) in rats or mice trained in hippocampal-dependent spatial or contextual learning tasks. We mentioned that differences in species, in training, or in recording protocols might account for this discrepancy. It is noticeable that the trained mutants, which showed a deficit in LTP maintenance, were also those exhibiting the higher amount of learning-induced spines. Since newly formed spines might not host fully functional synapses (Trachtenberg et al. 2002; Holtmaat et al. 2005), we can hypothesize that LTP decayed in this group because it was induced in immature hippocampal circuits. Alternatively, we could speculate that, contrary to associative spatial learning, contextual learning resulting from pseudotraining was not demanding enough to trigger hippocampal plastic changes interfering with LTP.

Altogether, our findings reveal that analysis of cellular changes induced by spatial training facilitates detection of hippocampal synaptic abnormalities in APP23 mutants. This observation parallels clinical reports indicating that recognizable symptoms of $\mathrm{AD}$ at early stages of the disease emerged only when patients are required to face unusual or complex cognitive activities. For example, patients diagnosed as mild cognitive impairment (MCI) show orientation deficits only when exposed to entirely new spatial settings (Hort et al. 2007). Supporting the view that effortful learning might elicit stronger reactive structural plasticity, MCI patients also show a paradoxical up-regulation of glutamatergic presynaptic boutons (Bell et al. 2007). Indeed, this issue suggests several methodological implications. In particular, if neuronal alterations selectively emerge in 
learning-activated hippocampal circuits, the search for synaptic defects in this or other mouse models of AD with disputable neurotransmission (Fitzjohn et al. 2001) or plasticity alterations (Chapman et al. 1999) might strongly benefit from being carried out under cognitive challenge.

\section{Acknowledgments}

We thank Dr. M. Staufenbiel (Novartis Pharma, Basel) for generously providing the APP23 mice. This work was supported by a grant from the Ministero della Salute RF0670M, Reg16 (to N.B.M.) and Ricerca Corrente IRCCS (to R.N.). We thank Mauro Federici for excellent technical assistance.

\section{References}

Abraham WC, Williams JM. 2008. LTP maintenance and its protein synthesis-dependence. Neurobiol Learn Mem 89: 260-268.

Bell KF, Bennett DA, Cuello AC. 2007. Paradoxical upregulation of glutamatergic presynaptic boutons during mild cognitive impairment. I Neurosci 27: 10810-10817.

Boncristiano S, Calhoun ME, Howard V, Bondolfi L, Kaeser SA, Wiederhold KH, Staufenbiel M, Jucker M. 2005. Neocortical synaptic bouton number is maintained despite robust amyloid deposition in APP23 transgenic mice. Neurobiol Aging 26: 607-613.

Chapman PF, White G, Jones MW, Cooper-Blacketer D, Marshall VJ, Irizzary M, Younkin L, Good MA, Bliss TV, Hyman BT, et al. 1999. Impaired synaptic plasticity and leaning in aged amyloid precursor protein transgenic mice. Nat Neurosci 2: 271-276.

Eyre MD, Richter-Levin G, Avital A, Stewart MG. 2003. Morphological changes in hippocampal dentate gyrus synapses following spatial learning in rats are transient. Eur J Neurosci 17: 1973-1980.

Fitzjohn SM, Morton RA, Kuenzi F, Roshal TW, Shearman M, Lewis H, Smith D, Reynolds DS, Davies CH, Colingride GL, et al. 2001. Age-related impairment of synaptic transmission but normal long term potentiation in transgenic mice that overexpress the human APP695SWE mutant form of amyloid precursor protein. J Neurosci 21: $4691-4698$.

Hellweg R, Lohmann P, Huber R, Kühl A, Riepe M. 2006. Spatial navigation in complex and radial mazes in APP23 animals and neurotrophin signaling as a biological marker of early impairment. Learn Mem 13: 63-71.

Holtmaat AJ, Trachtenberg JT, Wilbrecht L, Shepherd GM, Zhang X, Knott GW, Svoboda K. 2005. Transient and persistent dendritic spines in the neocortex in vivo. Neuron 45: 279-291.

Hort J, Laczó J, Vyhnálek M, Bojar M, Bures J, Vlcek K. 2007. Spatial navigation deficit in amnestic mild cognitive impairment. Proc Natl Acad Sci 104: 4042-4047.

Kelly PH, Bondolfi L, Hunziker D, Schlecht HP, Carver K, Maguire E, Abramowski D, Wiederhold KH, Sturchler-Pierrat C, Jucker M, et al. 2003. Progressive age-related impairment of cognitive behavior in APP23 transgenic mice. Neurobiol Aging 24: 365-378.

Knafo S, Grossman Y, Barkai E, Benshalom G. 2001. Olfactory learning is associated with increased spine density along apical dendrites of pyramidal neurons in the rat piriform cortex. Eur J Neurosci 13: 633-638.

Knafo S, Ariav G, Barkai E, Libersat F. 2004. Olfactory learning-induced increase in spine density along the apical dendrites of CA1 hippocampal neurons. Hippocampus 14: 819-825.

Kolb B, Whishaw IQ. 1998. Brain plasticity and behavior. Annu Rev Psychol 49: $43-64$.

Lalonde R, Dumont M, Staufenbiel M, Sturchler-Pierrat C, Strazielle C. 2002. Spatial learning, exploration, anxiety, and motor coordination in female APP23 transgenic mice with the Swedish mutation. Brain Res 956: $36-44$
Lange-Asschenfeldt C, Lohmann P, Riepe MW. 2007. Spatial performance in a complex maze is associated with persistent long-term potentiation enhancement in mouse hippocampal slices at early training stages. Neuroscience 147: 318-324.

Leuner B, Falduto J, Shors TJ. 2003. Associative memory formation increases the observation of dendritic spines in the hippocampus. J Neurosci 23: 659-665.

Makhracheva-Stepochkina D, Frey S, Frey JU, Korz V. 2008. Spatial learning in the holeboard impairs an early phase of long-term potentiation in the rat hippocampal CA1-region. Neurobiol Learn Mem 89: 545-551.

Meyer EP, Ulmann-Schuler A, Staufenbiel M, Krucker T. 2008. Altered morphology and $3 \mathrm{D}$ architecture of brain vasculature in a mouse model for Alzheimer's disease. Proc Natl Acad Sci 105: 3587-3592.

Middei S, Vetere G, Sgobio C, Ammassari-Teule M. 2007. Landmark-based but not vestibular-based orientation elicits mossy fiber synaptogenesis in the mouse hippocampus. Neurobiol Learn Mem 87: 174-180.

Mirochnic S, Wolf S, Staufenbiel M, Kempermann G. 2009. Age effects on the regulation of adult hippocampal neurogenesis by physical activity and environmental enrichment in the APP23 mouse model of Alzheimer disease. Hippocampus 19: 1008-1018.

Okuno H, Tokuyama W, Li YX, Hashimoto T, Miyashita Y. 1999. Quantitative evaluation of neurotrophin and trk mRNA expression in visual and limbic areas along the occipito-temporo-hippocampal pathway in adult macaque monkeys. J Comp Neurol 408: 378-398.

O’Malley A, O'Connell C, Murphy KJ, Regan CM. 2000. Transient spine density increases in the mid-molecular layer of hippocampal dentate gyrus accompany consolidation of a spatial learning task in the rodent. Neuroscience 99: 229-232.

Restivo L, Roman FS, Ammassari-Teule M, Marchetti E. 2006. Simultaneous olfactory discrimination elicits a strain-specific increase in dendritic spines in the hippocampus of inbred mice. Hippocampus 16: 472-479.

Restivo L, Vetere G, Bontempi B, Ammassari-Teule M. 2009. The formation of recent and remote memory is associated with time-dependent formation of dendritic spines in the hippocampus and anterior cingulate cortex. J Neurosci 29: 8206-8214.

Roder S, Danober L, Pozza MF, Lingenhoehl K, Wiederhold KH, Olpe HR. 2003. Electrophysiological studies on the hippocampus and prefrontal cortex assessing the effects of amyloidosis in amyloid precursor protein 23 transgenic mice. Neuroscience 120: 705-720.

Sacchetti B, Lorenzini CA, Baldi E, Bucherelli C, Roberto M, Tassoni G, Brunelli M. 2001. Long-lasting hippocampal potentiation and contextual memory consolidation. Eur I Neurosci 13: 2291-2298.

Sacchetti B, Lorenzini CA, Baldi E, Bucherelli C, Roberto M, Tassoni G, Brunelli M. 2002. Time-dependent inhibition of hippocampal LTP in vitro following contextual fear conditioning in the rat. Eur J Neurosci 15: $143-150$.

Selkoe DJ, Schenk D. 2003. Alzheimer's disease: Molecular understanding predicts amyloid-based therapeutics. Annu Rev Pharmacol Toxicol 43: 545-584.

Sturchler-Pierrat C, Abramowski D, Duke M, Wiederhold KH, Mistl C, Rothacher S, Ledermann B, Bürki K, Frey P, Paganetti PA, et al. 1997. Two amyloid precursor protein transgenic mouse models with Alzheimer disease-like pathology. Proc Natl Acad Sci 94: 13287-13292.

Syková E, Vorísek I, Antonova T, Mazel T, Meyer-Luehmann M, Jucker M, Hájek M, Ort M, Bures J. 2005. Changes in extracellular space size and geometry in APP23 transgenic mice: A model of Alzheimer's disease. Proc Natl Acad Sci 102: 479-484.

Trachtenberg JT, Chen BE, Knott GW, Feng G, Sanes JR, Welker E, Svoboda K. 2002. Long-term in vivo imaging of experience-dependent synaptic plasticity in adult cortex. Nature 420: 788-794.

Vloeberghs E, Van Dam D, D’Hooge R, Staufenbiel M, De Deyn PP. 2006. APP23 mice display working memory impairment in the plus-shaped water maze. Neurosci Lett 407: 6-10.

Zucker RS, Regehr WG. 2002. Short-term synaptic plasticity. Annu Rev Physiol 64: $355-405$.

Received January 8, 2010; accepted in revised form March 1, 2010. 


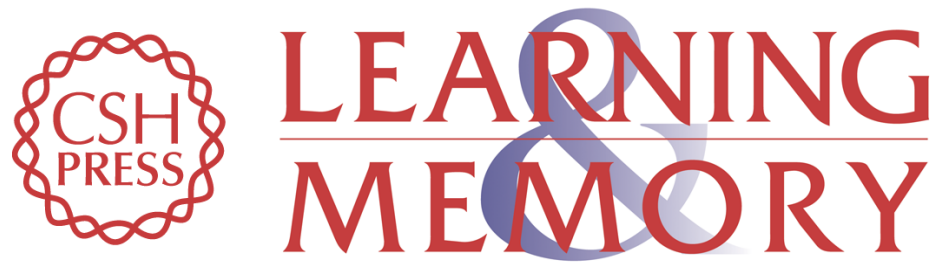

\section{Learning discloses abnormal structural and functional plasticity at hippocampal synapses in the APP23 mouse model of Alzheimer's disease}

Silvia Middei, Anna Roberto, Nicola Berretta, et al.

Learn. Mem. 2010, 17:

Access the most recent version at doi:10.1101/lm.1748310

References This article cites 33 articles, 9 of which can be accessed free at: http://learnmem.cshlp.org/content/17/5/236.full.html\#ref-list-1

License

Email Alerting

Receive free email alerts when new articles cite this article - sign up in the box at the Service top right corner of the article or click here. 